\title{
UnA DIOTA DE VIDRIO DE LA NECRÓPOLIS DE ORRIOLS (VALENCIA)
}

\section{MARÍA ASUNCIÓN MARTÍNEZ PÉREZ}

(1) Universitat de València.perez6@alumni.uv.es

La necrópolis de Orriols se localiza a las afueras de la ciudad de Valencia, en relación con el trazado próximo a la Vía Augusta, y se fecha en los ss. II y IV d.C. (Martínez Pérez en prensa $)^{1}$. En concreto la sepultura a la que hacemos referencia en estas páginas estaba situada en el no 262 de la Avenida de la Constitución (fig. 1), que se excavó en el año 2005 en el transcurso de unas obras, dado que la zona está protegida desde que se aprobó el Plan General de Ordenación Urbana de Valencia de 1988.

En el interior de una tumba de morfología ovalada, construida con piedras y fragmentos de tegulae trabados con mortero y cubierta de adobes, se depositan los restos de un individuo adulto de sexo masculino (fig. 2). La altura de las paredes y la profundidad de la tumba permiten atribuirle un carácter de monumentalidad. La sepultura se orienta en dirección N-S y el cadáver se coloca en posición decúbito supino. Tanto las fotografías que figuran en el informe de excavación (Guillén 2005), y que nos llevan a pensar que la descomposición del cadáver tuvo lugar en ambiente vacío, como los clavos que se encontraron en el interior del nicho nos informan de que probablemente el individuo fue enterrado en un ataúd de madera.
Como ajuar se introducen en la tumba la botella de vidrio a la que hacemos referencia y fauna de distintas especies. La diota ${ }^{2}$ se coloca en la zona norte de la sepultura, pero fuera del ataúd (fig. 3) y se encontraba fragmentada en el momento de la excavación, lo que llevó a su restauración.

\section{DIOTA DE VIDRIO}

Se trata de una botella de vidrio verde, cuerpo globular de tendencia oval, doble asa y base anillada, correspondiente con la forma 42 de Morin-Jean (1977: 95-97), 129 de Isings (1957: 159) y AR-176 de Rütti (1991: 175) (fig. 4). La base forma parte del tipo 5 de Morin-Jean (1977: 32-33), que según este autor surge en la Galia en el s. III, pero es común a partir del s. IV; mientras que las asas, decoradas con nervios longitudinales, se adscriben al tipo A1 de Morin-Jean (1977: 35), que las fecha en el s. III. La pieza está decorada con un cordón en la parte baja del cuello y con hilos de $1 \mathrm{~mm}$ de grosor en forma de espiral en la boca, que se abre ligeramente. Según Rütti (1991: 108) este cordón está presente en formas vítreas a 


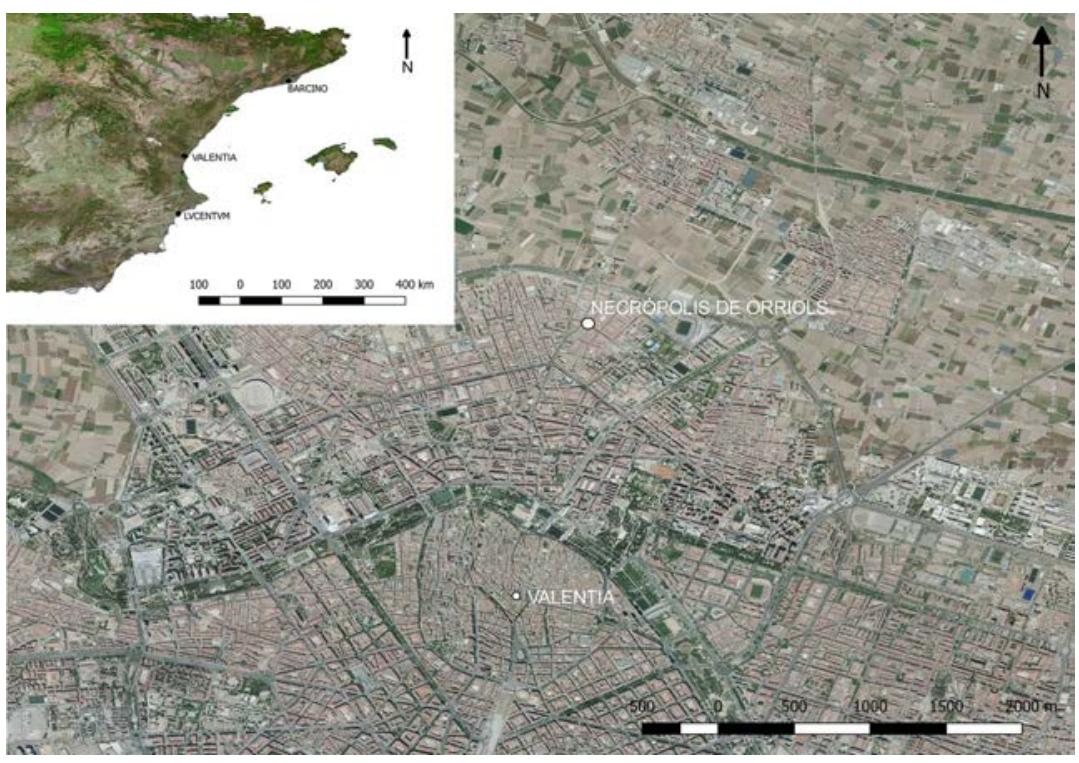

Fig. 1: Localización de la necrópolis de Orriols (Valencia).

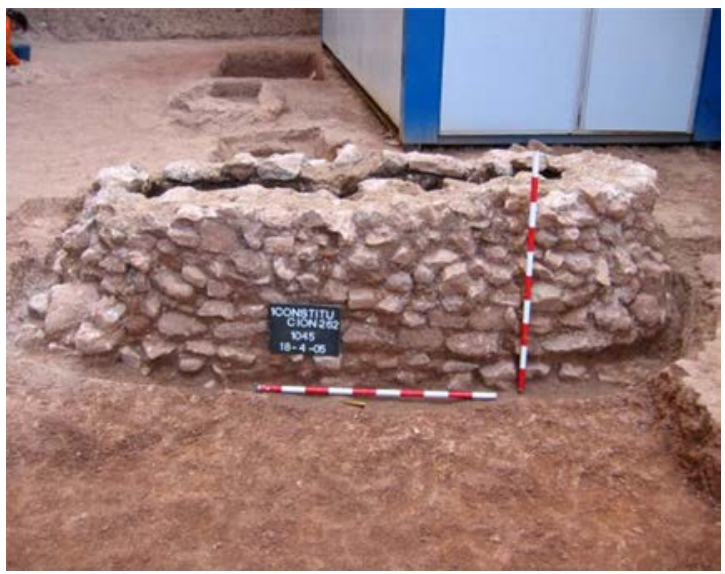

Fig. 2: Exterior de la tumba monumental. Archivo SIAM.

partir de los ss. III y IV. La decoración en forma de hilos se conoce como diseño esperiliforme o serpentiforme (Ortíz 2001: 114), se adscribe al grupo A de Morin-Jean (1977: 23-24), es muy común al final del Imperio y recuerda a las ligaduras que sujetarían el tapón de los recipientes. Los hilos se aplicaban en caliente para que se fundiesen con el resto del recipiente (Sánchez de Prado 1984: 93), lo que exige un control preciso de la temperatura. Aunque en un principio se pensó que este tipo de decoración era originaria de la zona de la Galia, Ortíz (2001: 114116) considera que fue introducida por artesanos sirios y alejandrinos en los talleres del área de Colonia a partir del s. IV con una menor calidad. Esta idea coincide con el planteamiento de Rütti, que considera que el tipo AR176 , junto con otros, pudo ser producido en talleres de la zona de Colonia (1991: 148).

Por la forma de las asas este tipo de recipientes -común en cerámica- reciben el nombre de diota, palabra originaria del mundo griego ( $\delta \iota \omega ́ \tau \eta)$ que puede traducirse como "con dos orejas". En el ámbito doméstico están destinados a contener líquidos como agua y vino (Arvellier-Dullong y Arvellier, 1985: 170-171), aunque la mayoría de paralelos se encuentran en contexto funerario. Es posible que en este ámbito se utilizasen en relación con el ritual de la unctura o como contenedor de ofrendas líquidas para el difunto.

En general estas piezas se fechan entre los ss. III y IV d.C., con ciertas variaciones en función de los autores. Así, Morin-Jean les atribuye una cronología entre los ss. III y IV d.C., mientras que Isings las fecha a partir del s. IV. Arveiller-Dullong y Arveiller (1985: 171-172) datan esta forma entre finales del s. III y el s. IV y la consideran típica de la zona oriental del Mediterráneo y el norte y noreste de la Galia. Sin embargo, se conocen ejemplos de época merovingia, como es el caso de la botella recogida por Morin-Jean (1977: 127), procedente de una de las sepulturas del cementerio de Arcy-Sainte-Restitue (Aisne, Francia), donde se depositan los restos de un adulto (Blase 2003: 498). Esto indica que esta forma continúa produciéndose en época tardoantigua. 


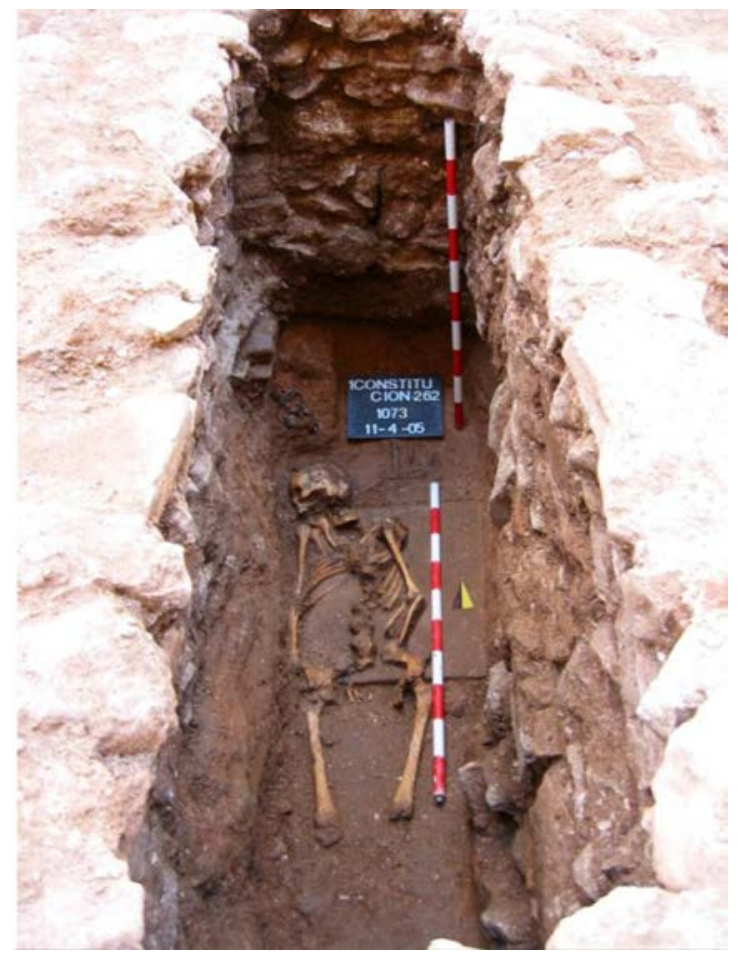

Fig. 3: Interior de la tumba monumental. En la zona norte se observa la diota de vidrio. Archivo SIAM.

\section{PARALELOS}

En la zona del Rin hemos identificado 17 paralelos. Seis de ellos proceden de la necrópolis de Porte Blanche (Estrasburgo) y se fechan entre la segunda mitad del s. III y la primera del s. IV d.C. Se caracterizan por la forma globular del cuerpo, las dos asas con diferente decoración y el cordón en la parte baja del cuello (Arvellier-Dullong y Arvellier 1985: Fig. 376-382, 171-172). Una de ellas se depositó en el interior de un cofre de madera y metal (Straub 1881: 48-9). En Châlons-enChampagne (Francia) se conserva otro ejemplar fechado entre los ss. III y IV d.C., que probablemente procede de una de las necrópolis de la zona (Lantier, 1929, $10)^{3}$. En el catálogo de vidrios de Augusta Raurica (Suiza) se recoge un ejemplar carente de decoración, que puede fecharse en el s. IV (Rütti 1991: 175). En otro ejemplar, que se cree procede de una de las sepulturas de la necrópolis de Vieuxville (Bélgica), la decoración se dispone sobre el cordón y está realizada en vidrio azul (Fontaine-Hodiamont 2007: 23-25). Por la combinación del vidrio verde y azul y el tipo de decoración se fecha a

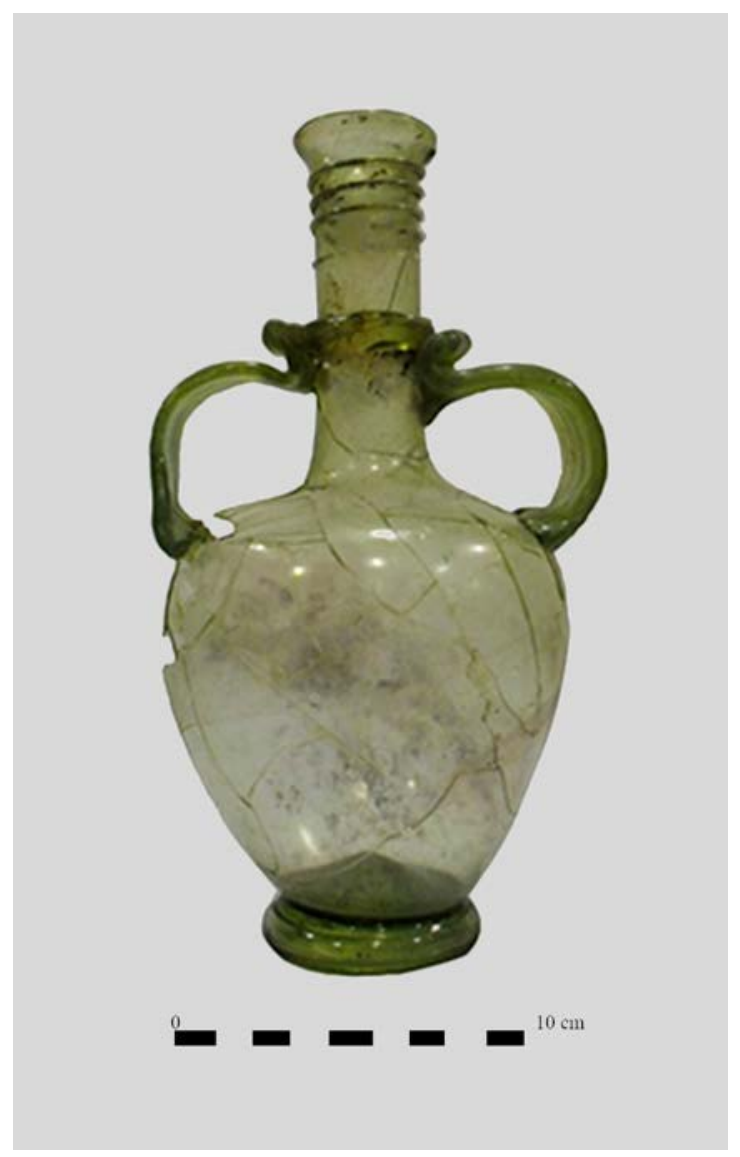

Fig. 4: Fotografía de la diota de vidrio.

partir de la segunda mitad del s. IV. En la necrópolis de Nempont-Saint-Firmin (Pas-de-Calais, Francia), se recuperaron tres ejemplares fechados en el s. IV y que acompañan a individuos adultos de sexo indeterminado. Una de ellas carece del cordón a la altura del cuello, mientras que otra presenta decoración en forma de acanaladuras en el cuerpo (Lelargue 2012: 6, 11). En necrópolis de Abbeville (Francia) se hallaron otros cinco ejemplares con distintos tipos de decoración (Pilloy 1880: 137, 151, 167, 196, 207).

De Bishopsbourne (Britania) procede un ejemplar que se fecha en el s. III d.C. y, según el dibujo, presenta decoración en la parte inferior del cuerpo; sin embargo, no hemos podido obtener más información (Cool y Price 1996: 151).

Solamente hemos encontrado tres paralelos que coincidan en la decoración y la forma con el ejemplar de Orriols. Uno de ellos forma parte de la colección del $M u$ sei di Storia ed Arte di Trieste (Italia) ( $\mathrm{n}^{\circ}$ de inventario: 


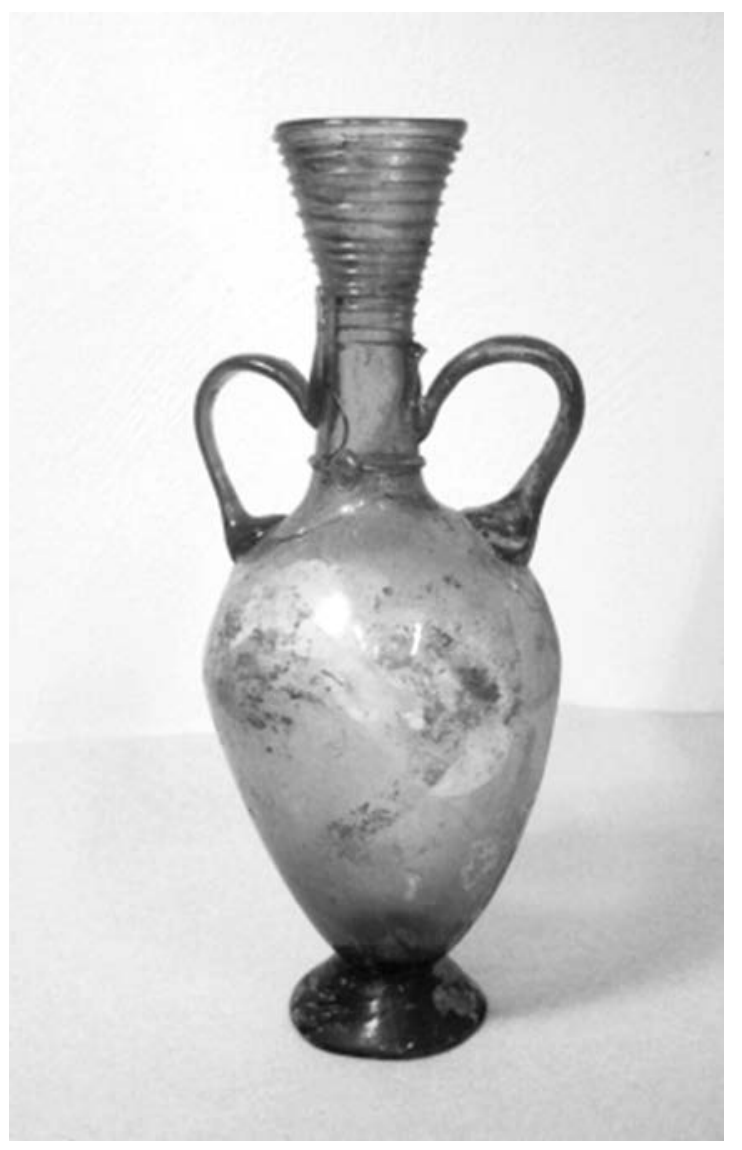

Fig. 5: Fotografía del ejemplar localizado en Trieste (Italia). Imagen cedida por el Musei di Storia ed Arte di Trieste (n. inv. 8394. Fototeca C.M.S.A. Trieste).
8394) (fig. 5). En este caso la boca tiene forma de embudo, pero la decoración está compuesta por hilos que se disponen en forma de espiral en la boca y un cordón en la parte baja. También se ha fechado en el s. IV d. C., aunque se desconoce su procedencia (Piussi 2008: 243-251). Según nos informan desde el museo, antes de formar parte de sus fondos pertenecía a una colección privada. En la península Ibérica, concretamente en La Rioja, encontramos otro paralelo, con la única diferencia en la forma del cuerpo (Hernández Vera et al. 2005). Otra diota de las mismas características y cronología se identifica en el área del teatro de Corinto. Aunque no conserva la base los autores le atribuyen una base anillada (Williams, Zervos 1983: Fig. 64). La presencia de esta botella en un complejo lúdico nos informa de que este tipo de recipientes se encuentran también en otros contextos.

\section{CONCLUSIONES}

La mayoría de los paralelos proceden del Valle del Rin (fig. 6), lo que concuerda con las hipótesis planteadas por Rütti y Ortiz, que piensan que el taller de producción de estas piezas y el origen en el Imperio romano de la decoración en forma de hilos tienen lugar en Colonia.

La forma y la decoración de la pieza permiten precisar su cronología en el s. IV, que coincide con el periodo de uso propuesto para la necrópolis de Orriols y los paralelos consultados. Esto nos aporta una cronología aproximada para fechar este enterramiento. Seguramente este recipiente

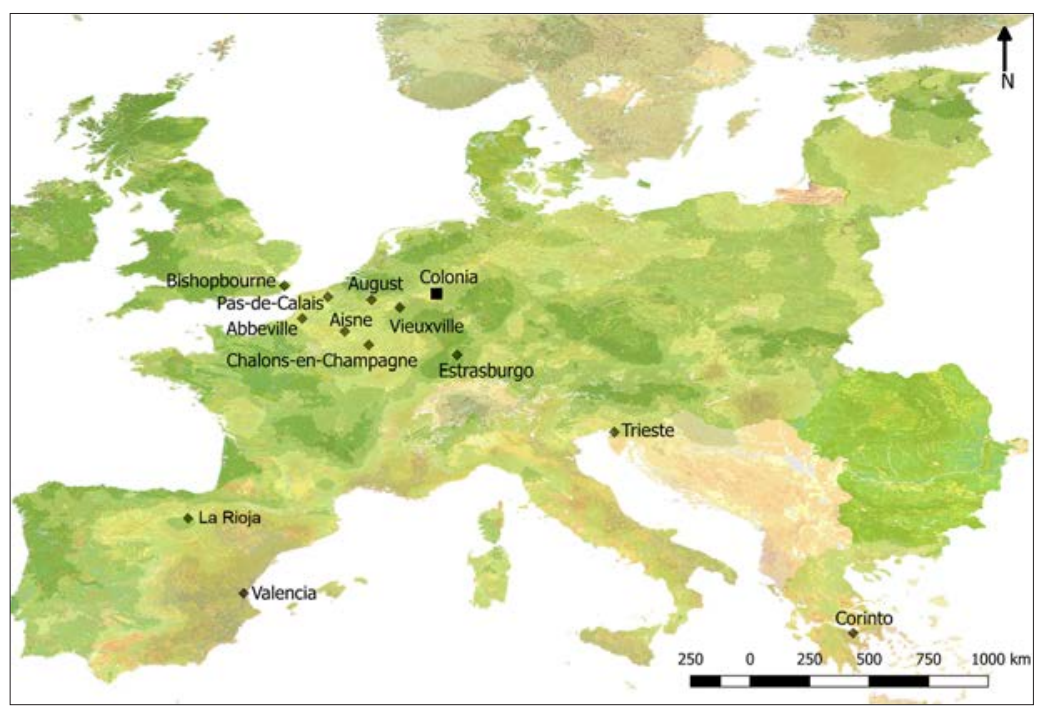

Fig. 6: Mapa de localización de los distintos ejemplares de diota mencionados. 
estuvo destinado a contener algún tipo de ofrenda líquida. Dado que en la sepultura también se identifican restos de fauna, pensamos que podría tratarse más de una ofrenda líquida, tal vez vino. Ortíz (2001: 26) apunta que la utilización de recipientes de vidrio podría estar relacionada con el uso de vino en el ritual funerario, que se vertería sobre la cabeza del difunto.

En la mayoría de casos desconocemos el sexo y la edad de los individuos junto a los que se depositaron estas piezas, a excepción de los casos de Augusta Raurica y Nempont-Saint-Firmin. El primer ejemplar se deposita en la sepultura de un individuo de 70 años y sexo masculino, al que se atribuye un estatus económico alto (Rütti 1991: 302). En Nempont-Saint-Firmin se trata de individuos adultos de sexo indeterminado. Por tanto, es probable que el uso de este tipo de recipientes se vincule a individuos adultos, lo que concuerda con la idea del uso de vino como ofrenda líquida.

\section{NOTAS}

1. Tanto los materiales como los informes de excavación se encuentran en los almacenes del Servicio de Investigación Arqueológica Municipal del Ajuntament de València, del que recibimos el permiso de estudio para nuestro Trabajo Final de Máster en Arqueología (Universitat de València) en el curso 2014-2015.

2. Esta pieza forma parte de la exposición sobre vidrios en Valencia organizada por la Delegación de Cultura del Ajuntament de València en 2015 en el centro arqueológico de l'Almoina. En relación con esta exposición, se hace referencia a esta botella en la publicación editada por M. A. Ramón (2015).

3. $\mathrm{N}^{\circ}$ inv. en Europeana Collections: 31388 . Agradecemos la información proporcionada por el Musée d'Archéologie Nationale et domaine national de Saint-Germain-en-Laye Château (Francia).

\section{AGRADECIMIENTOS}

Al profesor Ferran Arasa i Gil, director de nuestro Trabajo Final de Máster, y al Servicio de Investigación Arqueológica Municipal por permitirnos el acceso a los materiales e informes de esta necrópolis.

A Maria Dolores Sánchez de Prado por la información referida a la diota procedente de La Rioja.

\section{BIBLIOGRAFÍA}

ARVELLIER-DULONG, V.; ARVELLIER, J. (1985): Le verre d'époque romaine au Musée archéologique de Strasbourg, París.
BLASE, P. (2003): Carte Archéologique de la Gaule 02 : L'Aisne, París.

COOL, H.; PRICE, J. (1996): Colchester Archaeological Report 8: Roman vessel glass from excavations in Colchester, 197185, vol. 135, Colcherter.

FONTAINE-HODIAMONT, C. (2004-2005): La diota de Vieuxville et la Cruche de Crupet : approche technologique, analyses et restauration de deux verres romains tardifs. Description archéologique et traitement, Bulletin de l'Institut Royal du Patrimoine Artistique/Instituut voor het Kunstpatromonium 31, 19-38.

GUILLÉN, C. (2005): Intervención arqueológica en la Avenida de la Constitución $N^{\circ} 262$, Valencia, memoria inédita, archivo SIAM.

HERNÁNDEZ VERA, J. A.; NÚÑ̃Z, J.; MARTÍNEZ, J. M. (2005): La romanización, Historia del Arte en La Rioja. De la Prehistoria a la Antigüedad Tardía (J. G. Moya, dir., B. Arrué, coord.), Logroño, 103-173.

ISINGS, C. (1957): Roman Glass from dated finds, Utrecht.

LANTIER, R. (1929): La verrerie. Musée des Antiquités nationales. Saint-Germain-en-Laye, París.

LELARGE, S. (2012): Le mobilier en verre de la nécropole de Nempont-Saint-Firmin (Pas-de Calais), Le verre en Lorraine et dans les régions voisines (V. Arvellier, H. Cabart, dirs.), Montagnac, 1-26 <https://www.academia. edu/20010484/Le_mobilier_en_verre_de _ la_n\%C3\%A9cropole_de_Nempont-Saint-Firmin_Pas-deCalais_-_S._Lelarge> (Consulta 10-VI-2016).

MARTÍNEZ PÉREZ, M. A. (en prensa): La necrópolis de Orriols (Valencia): ejemplos de ritual funerario en época romana (siglos II-IV d. c), Lucentum, 35.

MORIN, J. (1977): La verreire en Gaule sous l'Empire Romain, Nogent-le-Roi.

ORTIZ, E. (2001): Vidrios procedentes de la provincia de Zaragoza: el Bajo Imperio Romano (Catálogo de fondos del Museo de Zaragoza), Zaragoza.

PILLOY, J. (1880): Études sur d'anciens Lieux de Sépulture dans l'Aisne, vol. 1, Aisne.

PIUSSI, S. (2008): Cromazio di Aquileia: al crocevia di genti e religioni, Milán.

RAMÓN, M. A. (Ed.) (2015): El vidrio antiguo en Valencia, Quaderns de difusió arqueológica 12, València

RÜTTI, B. (1991): Die römischen gläser aus August und Kaisesaraugust, Augst.

SÁNCHEZ DE PRADO, M. D. (1984): El vidrio romano en la provincia de Alicante, Lucentum 3, 79-100.

STRAUB, A. (1881): Le cimetière Gallo-Romain de Strasbourg, Strasbourg.

WILLIAMS, C. K.; ZERVOS, O. H. (1983): Corinth, 1982: East of the Theater, Hesperia: The Journal of the American School of Classical Studies at Athens 52, 1-47. 